\title{
Analisis Karakteristik Gaya Belajar VAK (Visual, Auditori, Kinestetik) Siswa Pada Pembelajaran Fisika
}

\author{
Syahriani Yulianci ${ }^{1)}$, Nurjumiati ${ }^{1) *}$, Asriyadin $^{1)}$ \\ ${ }^{1)}$ STKIP Taman Siswa Bima \\ ${ }^{2)}$ Universitas Samawa \\ *nurjumiati100@gmail.com
}

Abstrak: Gaya belajar siswa merupakan salah satu info penting yang perlu diperoleh sebelum guru melakukan kegiatan pembelajaran, agar guru dapat menentukan desain pembelajaran yang cocok pada kelas tersebut. Penelitian deskriptif kualitatif ini bertujuan untuk menganalisis karakteristik gaya belajar siswa. Subjek penelitian terdiri dari 74 siswa yang merupakan siswa kelas X di salah satu Madrasah Aliyah di Kabupaten Bima. Penentuan sampel dilakukan secara purposive sampling. Instrumen gaya belajar berupa angket berbentuk pilihan ganda, dengan jumlah 22 butir soal, dan masing-masing soal memiliki tiga pilihan jawaban. Gaya belajar yang diteliti fokus pada gaya belajar Visual, Auditori, dan Kinestetik. Data dianalisis secara kualitatif dan kuantitatif. Data yang diperoleh, siswa lebih cenderung pada gaya belajar Auditori dengan jumlah 51\%, sedangkan Visual sebanyak $14 \%$ dan Kinestetik sebanyak 15\%. Selain itu juga ditemukan kecenderungan gaya belajar yang persentase dimiliki sama besar, yaitu gabungan Visual Auditori sebesar 8\% dan gabungan Auditori Kinestetik 12\%. Sehingga dari penelitian ini dapat disimpulkan bahwa siswa kelas X yang mengikuti pembelajaran fisika lebih cenderung pada gaya belajar auditori. Guru yang akan mengajar di kelas tersebut dapat menyesuaikan model dan media pembelajaran yang sesuai dengan gaya belajar yang dimiliki oleh siswa.

Kata Kunci: Gaya Belajar, Fisika, Visual, Auditori, Kinestetik

\section{Pendahuluan}

Salah satu hal yang menentukan hasil belajar ataupun prestasi belajar siswa adalah dari proses pembelajarannya. Seorang guru yang profesional akan menggunakan teknik pembelajaran yang sesuai dalam kelasnya. Kesesuain materi dengan model pembelajaran yang digunakan, maupun kesesuian model pembelajaran dengan karakteristik siswa merupakan beberapa hal yang perlu dipertimbangkan oleh guru sebelum mengajar. Salah satu karakteristik siswa yang perlu diperhatikan adalah gaya belajar siswa (Sari, 2014).

Gaya belajar menurut Kolb adalah cara yang cenderung dipilih seseorang untuk menerima informasi dalam lingkungannya dan memproses informasi (Yulianci et al., 2018); (Marpaung, 2016). Mengetahui gaya belajar siswa, akan mempermudah guru untuk menyediakan lingkungan yang mendukung dan mempermudah siswa menyerap informasi secara maksimal (Widayanti, 2013), sehingga guru perlu mengetahui jenis gaya belajar yang digunakan oleh setiap siswa. Setiap siswa memiliki gaya belajar yang berbeda-beda dalam menerima dan memahami materi pelajaran.

Ada tiga jenis gaya belajar yaitu visual, auditori dan kinestetik. Gaya belajar visual, auditori dan kinestetik akan memperngaruhi hasil belajar atau prestasi siswa (Azis, 2020). Menurut De Poter \& Hernachi menjelaskan secara umum gaya belajar siswa dibedakan ke dalam tiga jenis yaitu gaya belajar visual, gaya belajar auditorial dan gaya belajar kinestetik. Gaya belajar visual adalah gaya belajar dengan cara melihat, mengamati, memandang dan sejenisnya. Gaya belajar auditorial adalah gaya belajar dengan cara mendengar. Gaya belajar kinestetik adalah gaya belajar dengan cara bergerak, bekerja dan menyentuh (Papilaya et al., 2016). Siswa akan mudah memahami materi pelajarannya jika mereka menemukan gaya belajar meraka sendiri. Menurut Barbara Prashning penyerapan informasi bergantung pada cara orang untuk mendapatkan informasi tersebut (Marpaung, 2015).

Fisika adalah pengtahuan fisis, maka untuk memepelajari fisika dan memebentuk pengetahuan tentang fisika diperlukan kontak langsung dengan hal yang ingin diketahui. Dalam proses pembelajaran fisika yang 
terpenting adalah siswa aktif belajar, sedangkan guru menguasai bahan yang diajarkan (Chodijah et al, 2012). Selain itu, pembelajaran fisika siswa tidak hanya mendengar, mencatat dan mengingat dari materi pelajaran tetapi lebih ditekankan pada kemampuan peserta didik dalam memecahkan persoalan. Keberhasilan dalam mempelajari fisika dipengaruhi oleh beberapa faktor, salah satunya faktor internal siswa, yaitu gaya belajar yang digunakan oleh siswa dalam memepelajari fisika.

Berdasarkan hasil wawancara yang dilakukan dengan salah satu guru mata pelajaran fisika kelas sepuluh, di dapatkan informasi bahwa terdapat 70\% siswa memiliki nilai fisika di atas batas minimum, sedangkan 30\% siswa dibawah batas minimum atau dibawah KKM. Keberhasilan dan kegagalan siswa dalam mencapai nilai di atas KKM dipengaruhi oleh beberapa faktor tertentu, salah satunya yaitu gaya belajar. Hasil belajar siswa yang telah diperoleh tidak terlepas dari kerja keras siswa dalam belajar, tentunya dengan menerapkan gaya belajar yang dimiliki masing-masing siswa. Selain itu, hasil wawancara menunujukkan bahwa guru tidak mengenali atau memahami karakteristik gaya belajar yang dimiliki oleh siswa. Padalah memahami gaya belajar siswa merupakan salah hal yang terpenting dan berpengaruh dalam proses pembelajaran (Cahyani, 2016).

Salah satu penelitian yang dilakukan oleh Saputri membuktikan bahwa terdapat pengaruh yang signifikan gaya belajar terhadap prestasi belajar siswa. Koefisien gaya belajar visual sebesar 0,127 , koefisien gaya belajar auditorial sebesar 0,166 dan koefisien gaya belajar kinestetik sebesar 0,148. Semakin tinggi penggunaan gaya belajar, maka semakin tinggi prestasi belajar siswa (Saputri, 2016). Pada dasarnya setiap siswa memiliki gaya belajar tersebut. Untuk mengetahui gaya belajar yang dimiliki siswa, maka diperlukan suatu penelitian agar dapat memahami macam-macam gaya belajar yang dimiliki siswa, khusunya pada pembelajaran fisika. Adanya informasi terkait dengan macam-macam atau karakteristik gaya belajar yang dimiliki siswwa, maka pengajar dapat meningkatkan kualitas atau memperbaiki proses pembelajaran yang dilakukan. Oleh karena itu, tujuan penelitian ini yaitu untuk mendeskripsikan hasil analisis karakteristik gaya belajar siswa pada pembelajaran fisika.

\section{Metode}

Penelitian ini termasuk dalam jenis penelitian deskriptif kualitatif. Sampel penelitian ditentukan secara purposive sampling. Sampel penelitian berjumlah 74 siswa yang terdiri dari 36 siswa pada kelas A dan 38 siswa pada kelas B. Instrument yang dibagikan berbentuk pilihan ganda. Jumlah butir soal pada instrument sebanyak 22 soal. Pada tiap soal terdapat tiga pilihan jawaban. Pilihan jawaban masing-masing menggambarkan jenis gaya belajar yang diteliti. Pilihan jawaban "A" menggambarkan gaya belajar Visual, pilihan jawaban "B" menggambarkan gaya belajar Auditori, sedangkan pilihan jawaban " $\mathrm{C}$ " menggambarkan gaya belajar Kinestetik. Data yang diperoleh akan dianalisis secara persentase.

\section{Hasil dan Pembahasan}

Gaya belajar merupakan cara siswa dalam memperoleh dan mengolah informasi. Penelitian ini bertujuan untuk menganalisis kecederungan jenis gaya belajar dari tiap siswa saat belajar fisika. Setiap orang memiliki gaya belajar yang berbeda-beda. Namun dalam proses pembelajaran, gaya belajar pada umumnya dapat dikategorikan menjadi tiga, yaitu Visual, Auditori, dan Kinestetik. Siswa yang memiliki gaya belajar Visual bukan berarti tidak memiliki sifat gaya belajar lainnya, hanya saja siswa Visual akan lebih mudah menerima dan mengolah informasi saat guru menerangkan melalui gambar. Gaya belajar Auditori siswa lebih mudah memahami dengan cara mendengar, sedangkan kinestetik dengan melakukan atau praktek langsung.

Berdasarkan hasil analisis data, siswa memiliki lima jenis kecenderungan gaya belajar, di antaranya visual (V), auditori (A), kinestetik (K), gabungan visual dan auditori (VA), serta gabungan auditori dan kinestetik (AK). Tabel 1 menampilkan persentase dari tiap kecenderungan gaya belajar siswa.

Tabel 1. Persentase Kecenderungan Gaya Belajar Siswa

\begin{tabular}{cccc}
\hline No. & Gaya Belajar & Frekuensi & Persentase (\%) \\
\hline 1 & V & 10 & 14 \\
2 & A & 38 & 51 \\
3 & K & 11 & 15 \\
4 & VA & 6 & 8 \\
5 & AK & 9 & 12 \\
\hline
\end{tabular}


Berdasarkan Tabel 1, persentase gaya belajar auditori memiliki persentase yang lebih besar dibandingkan gaya belajar lainnya, bahkan jumlahnya lebih besar lima kali lipat dari gaya belajar gabungan visual dan auditori yang persentasenya hanya $8 \%$. Kecenderungan gaya belajar yang sangat kecil persentasenya adalah gabungan visual auditori. selain itu jika dikategorikan berdasarkan kelas, kelas A memiliki jumlah 36 siswa dan kelas B sebanyak 38 siswa. Gambar 1 akan menampilkan persentase gaya belajar kelas A, dan Gambar 2 akan menampilkan persentase gaya belajar kelas B.

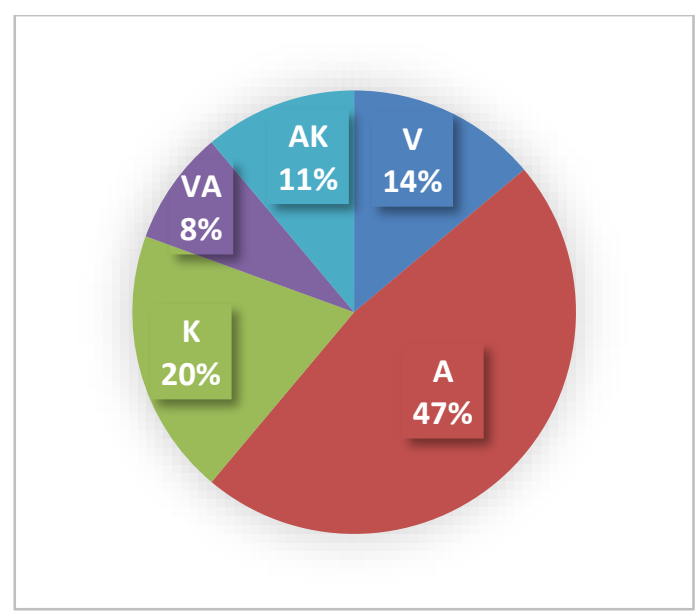

Gambar 1. Persentase Gaya Belajar Siswa Pada Kelas A

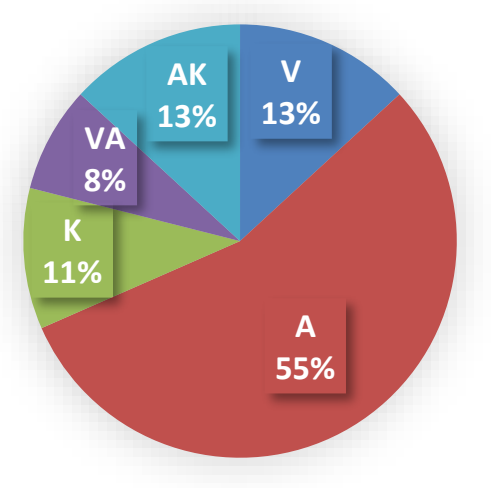

Gambar 2. Persentase Gaya Belajar Siswa Pada Kelas B

Siswa kelas A dan kelas B lebih cenderung pada gaya belajar auditori dengan masing-masing persentase sebesar $47 \%$ dan 55\%. Hal ini memperlihatkan bahwa selisih antara kelas A dan kelas B pada gaya belajar auditori hanya berbeda $8 \%$. Kesamaan lainnya antara kelas A dan kelas B, gaya belajar yang paling sedikit dimiliki adalah gabungan Visual Auditori (VA).

Pendidik mendapatkan info karakteristik unik dari siswa salah satunya melalui identifikasi gaya belajar. Sehingga dengan beberapa keunikan yang dimiliki siswa, guru dapat memaksimalkan pengajaran. Seorang pendidik dapat berkreasi dalam proses pembelajaran. Bukan suatu hal yang mustahil jika seorang siswa memiliki ketiga gaya belajar tersebut. Hanya saja tiap siswa selalu memiliki jenis kecenderungan gaya belajar yang berbeda. Gaya belajar siswa penting untuk diketahui oleh guru, karena dengan cara itu, guru dapat menyesuaikan model pembelajaran ataupun media pembelajaran dalam penyampain materi sehingga dapat meningkatkan pemahaman siswa pada materi tersebut.

Gaya belajar pada umumnya berpengaruh terhadap suatu kemampuan siswa. Hal ini dibuktikan oleh beberapa hasil penelitian di antaranya (Arylien Ludji Bire, Uda Geradus, 2014) (Ekonomi et al., 2003) siswa visual akan sulit menerima proses pembelajaran hanya dengan cara berbicara atau mendegarkan. Sehingga metode ceramah kurang cocok jika diimplementasikan pada siswa visual. Pada siswa visual, indra penglihatan memegang peran yang sangat penting. Sehingga dalam proses pembelajaran untuk siswa visual guru dapat menyajikan informasi dari gambar, atau grafik ataupun secara tertulis. Beberapa ciri-ciri siswa yang memiliki gaya kecenderungan gaya belajar visual antara lain teratur, memperhatikan segala sesuatu, menjaga penampilan, 
mengingat dengan gambar, lebih suka membaca daripada dibacakan dan membutuhkan gambaran dan tujuan menyeluruh.

Siswa auditori lebih mudah menerima informasi melalui pendengaran. Siswa auditori akan mudah terganggu oleh kebisingan saat iya belajar. Mereka lebih suka berdiskusi dan mejelaskan sesuatu info dengan Panjang lebar dibandingkan hanya dengan melihat info tersebut melalui gambar. Oleh karena itu guru dalam hal ini dapat mengajarkan siswa dengan metode ceramah, atau memberikan info melalui audio. Sedangkan siswa dengan gaya belajar kinestetik, lebih mudah mendapatkan info apabila dia terlibat langsung. Misalnya dengan menyentuh atau mempraktekkan langsung. Siswa-siswa auditori memiliki ciri-ciri antara lain perhatiannya mudah terpecah, berbicara dengan pola berirama, belajar dengan cara mendengarkan, menggerakkan bibir/bersuara saat membaca, berdialog secara internal dan eksternal.

Gerakan, koordinasi, irama, tanggapan emosional, dan kenyamanan fisik sangat menonjol pada mahasiswa yang sangat kinesterik. Ciri-ciri siswa kinestetik antara lain sering menyentuh orang, berdiri berdekatan, dan bergerak saat berinteraksi dengan orang lain belajar dengan melakukan, menunjuk tulisan saat membaca, mengingat sambil berjalan dan melihat. Pembelajaran fisika memiliki materi yang sangat kompleks, mulai dari benda yang ukuran mikro sampai dengan ukuran makro. Konsep fisika dan teori-teori fisika tidak bisa diajarkan hanya dengan metode ceramah. Karena banyak konsep yang perlu dibuktikan dalam proses pembelajarannya.

Gaya belajar seseorang dapat berubah tergantung dari kebiasaannya. Siswa yang dibiasakan dengan pengajaran secara visual atau auditori ataupun secara kinestetik, maka bukanlah hal yang tidak mungkin gaya belajar siswa mengikuti cara mengajar guru. Hal ini sesuai dengan penelitian Abdul Halim (2017) bahwa adanya interaksi strategi mengajar dan gaya belajar siswa dalam mempengaruhi hasil belajar.

\section{Simpulan}

Berdasarkan hasil analisis data, pembahasan beserta tujuan penelitian, dapat disimpulkan bahwa siswa kelas $\mathrm{X}$ yang mengikuti pembelajaran fisika lebih cenderung pada gaya belajar auditori. Siswa lebih cenderung pada gaya belajar Auditori dengan jumlah 51\%, sedangkan Visual sebanyak 14\% dan Kinestetik sebanyak 15\%. Selain itu juga ditemukan kecenderungan gaya belajar yang persentase dimiliki sama besar, yaitu gabungan Visual Auditori sebesar 8\% dan gabungan Auditori Kinestetik 12\%.

\section{Ucapan Terima Kasih}

Peneliti mengucapkan terima kasih kepada Kemenristekdikti/BRIN dalam rangka pemberian hibah Penelitian Dosen Pemula dan STKIP Taman Siswa Bima sehingga penelitian ini dapat terlaksana.

\section{Daftar Pustaka}

Arylien ludji bire, uda geradus, dan j. B. (2014). Pengaruh gaya belajar visual, auditorial, dan kinestetik terhadap prestasi belajar siswa. Pengaruh gaya belajar visual, auditorial, dan kinestetik terhadap prestasi belajar siswa, 44(2). Https://doi.org/10.21831/jk.v44i2.5307

Azis, F. R. N., Pamujo, P., \& Yuwono, P. H. (2020). Analisis Gya Belajar Visual, Auditorial, Kinestetik Siswa Berprestasi di SD Negeri Ajobarang Wetan. Jurnal Mahasiswa BK An-Nur: Berbeda, Bermakna, Mulia, 6(1), 26-31.

Cahyani, I. S. (2016). Pentingnya Mengenali Gaya Belajar Siswa dam Kegiatan Pembelajaran. Jurnal Ilmiah Universtas Negeri Malang.

Chodijah, S., Fauzi, A., \& Ratnawulan, R. (2012). Pengembangan Perangkat Pembelajran fisika menggunakan Model Guided Inquiry yang Dilengkapi Penilaian Portofolio pada Materi Gerak Melingkar. Jurnal Penelitian Pembelajara Fisika. 1(1).

Ekonomi, f., surabaya, u. N., surabaya, k. K., \& surabaya, j. K. (2003). Terhadap hasil belajar mata pelajaran ekonomi di kelas $x$ sma negeri 18 surabaya Cintya Septiana Andri Astutie. 20, 1-15.

Halim, A. Pengaruh Strategi Pembelajaran dan Gaya Belajar Terhadap Hasil BELAJAR Fisika. Jurnal Teknologi Pendidikan (JPT), 10(2).

Marpaung, J. (2016). Pengaruh Gaya Belajar Terhadap Prestasi Belajar Siswa. KOPASTA: Jurnal Program Studi Bimbingan Konseling, 2(2), 13-17. https://doi.org/10.33373/kop.v2i2.302

Papilaya, J. O., \& Huliselan, N. (2016). Identifikasi Gaya Belajar Mahasiswa. Jurnal Psikologi, 15(1), 56-63

Sari, A. K (2014). Analisis Karakteristik Gaya Belajar VAK (Visual, Auditorial, Kinestetik) Mahasiswa Pendidikan Informatika Angkaan 2014. Education Scientifik Journal of informatics Education, 1(1) 
Saputri, F. I. (2016). Pengaruh Gaya Belajar Visual, Auditori, dan Kinestetik Terhadap Prestasi Bejajar Siswa. Jurnal Prima Edukasia, 3(01), 25-36.

Widayanti, F. D. (2013). Pentingnya Mengetahui Gaya Belajar Siswa Dalam Kegiatan Pembelajaran Di Kelas. Erudio Journal of Educational Innovation, 2(1). https://doi.org/10.18551/erudio.2-1.2

Yulianci, S., Gunawan, G., \& Doyan, A. (2018). The Effect of Guided Inquiry Model with Interactive Multimedia Towards Student's Generic Science Skill Based on Learning Styles. Aes, 193-198. https://doi.org/10.5220/0007301001930198 